\title{
Comparison of clinical effects according to the dosage of sufentanil added to $0.5 \%$ hyperbaric bupivacaine for spinal anesthesia in patients undergoing cesarean section
}

\author{
Yun Sic Bang, Kum-Hee Chung, Jung Hyang Lee, Seung-Ki Hong, Seok Hwan Choi, Jong-Yeon Lee, \\ Su-Yeon Lee, and Hyeon Jeong Yang \\ Department of Anesthesiolgy and Pain Medicine, CHA Bundang Medical Center, CHA University, Seongnam, Korea
}

Background: Subarachnoid block is a widely used technique for cesarean section. To improve the quality of analgesia and prolong the duration of analgesia, addition of intrathecal opioids to local anesthetics has been encouraged. We compared the effects of sufentanil $2.5 \mu \mathrm{g}$ and $5 \mu \mathrm{g}$, which were added to intrathecal hyperbaric bupivacaine.

Methods: We enrolled 105 full term parturients were randomly divided into 3 groups: Group 1 (control), Group 2 (sufentanil $2.5 \mu \mathrm{g}$ ), and Group 3 (sufentanil $5 \mu \mathrm{g}$ ). In every group, 0.5\% heavy bupivacaine was added according to the adjusted dose regimen. We determined the maximum level of sensory block and motor block, the quality of intraoperative analgesia, the duration of effective analgesia and side effects.

Results: There were no significant differences among the 3 groups in the maximum level of the sensory block and motor block. Recovery rate of the sensory block, however, was significantly slower in Group 3 than Group 1. Quality of intraopertive analgesia, muscle relaxation, and duration of effective analgesia were enhanced by increasing the dosage of intrathecal sufentanil. Frequencies of hypotension, maximum sedation level, and pruritus were directly related to the dosage of intrathecal sufentanil, whereas nausea and vomiting occurred only in the groups using sufentanil.

Conclusions: The addition of sufentanil $2.5 \mu \mathrm{g}$ for spinal anesthesia provides adequate intraoperative analgesia and good postoperative analgesia with minimal adverse effects on the mother. (Korean J Anesthesiol 2012; 63: 321-326)

Key Words: Bupivacaine, Cesarean section, Spinal anesthesia, Sufentanil.

\footnotetext{
Received: March 7, 2012. Revised: 1st, April 17, 2012; 2nd, April 30, 2012; 3rd, May 5, 2012; 4th, May 7, 2012. Accepted: May 9, 2012. Corresponding author: Kum-Hee Chung, M.D., Department of Anesthesiolgy and Pain Medicine, CHA Bundang Medical Center, CHA University, 59, Yatap-ro, Bundang-gu, Seongnam 463-712, Korea. Tel: 82-31-780-1837, Fax: 82-31-780-5566, E-mail: anesthkh@cha.ac.kr (c) This is an open-access article distributed under the terms of the Creative Commons Attribution Non-Commercial License (http:// creativecommons.org/licenses/by-nc/3.0/), which permits unrestricted non-commercial use, distribution, and reproduction in any medium, provided the original work is properly cited.
} 


\section{Introduction}

Spinal anesthesia is often used for cesarean section and is favored over epidural anesthesia due to the ease of maneuver, rapid onset, effective sensory and motor block, low failure rate and low systemic toxicity [1,2]. Adding an opioid to the intrathecally administered local anesthetic solution is a widely used method for improving the intraoperative and early postoperative quality of the subarachnoid block and reducing intraoperative visceral traction pain $[3,4]$.

Morphine is a highly-ionized, hydrophilic opioid, which provides a spinal analgesia of slow onset and long duration, but has side-effects such as nausea, vomiting, pruritus, and late respiratory depression [5]. On the other hand, the addition of lipophilic opioids, such as fentanyl and sufentanil to local anesthetics, shortens the onset time of the block but produces a lower incidence of side-effects compared with morphine [2,6]. Although several reports have shown to compare the effects of adding various opioids to a fixed amount of local anesthetic solution administered intrathecally [1-7], there have not been studies that have compared effects of adding various opioids to varying amount $0.5 \%$ hyperbaric bupivacaine based on the parturients heights and weights.

The aim of the present investigation was to determine the appropriate amount of sufentanil addition to $0.5 \%$ hyperbaric bupivacaine to minimize the side effects and maximize the analgesic effect.

\section{Materials and Methods}

The study was performed in a randomized, double-blind fashion after approval by the institutional review board and with the informed written consent of 105 ASA (American Society of Anesthesiologists) physical status I-II women scheduled for elective cesarean section. We excluded parturients who had contraindications to spinal anesthesia or a high risk of gestational hypertension, diabetes and/or placenta previa.

One-hundred-five, healthy term parturients were randomly divided into three groups: Group 1 (control; normal saline 0.2 $\mathrm{ml}$ ), Group 2 (sufentanil $2.5 \mu \mathrm{g}+$ normal saline $0.15 \mathrm{ml}$ ), Group 3 (sufentanil $5 \mu \mathrm{g}+$ normal saline $0.1 \mathrm{ml}$ ). In every group, $0.5 \%$ heavy bupivacaine was added according to the adjusted dose regimen by Harten et al. [8] (Table 1). In order to determine sample sizes, power analysis was performed. In respect to the variable of effective analgesia duration the power analysis was done (alpha $=0.05$, power $=80 \%$, effect size $=0.5$ ) and 35 parturient were assigned in each group. No subject received premedication and at their arrival into the operating room (OR) they were intravenously injected with $10 \mathrm{ml} / \mathrm{kg}$ Ringer's lactate solution via an $18-\mathrm{G}$ venous catheter until the induction of anesthesia. The electrocardiogram (EKG), a non-invasive auto-blood pressure (BP) measurement instrument and pulse oximetry were set up for monitoring the vital signs, while oxygen was provided at $5 \mathrm{~L} / \mathrm{min}$ using face mask ventilation until the end of the operation.

To perform spinal anesthesia, the patients were placed into a right lateral decubitus position and after the needle insertion site was disinfected, a dural puncture was made with a 26-G Whitacre spinal needle at the L3-L4 or L2-L3 lumbar vertebrae space. The location of the subarachnoid space was then confirmed by the leakage and aspiration of cerebrospinal fluid (CSF). Each hyperbaric solution of bupivacaine (Table 1) was slowly injected over 30 seconds: there was no addition of opioid for Group 1, sufentanil $2.5 \mu \mathrm{g}$ was added for Group 2

Table 1. The Adjusted Dose Regimen for Hyperbaric Bupivacaine 0.5\% When Used for Spinal Anesthesia for Cesarean Section (ml)

\begin{tabular}{|c|c|c|c|c|c|c|c|c|c|}
\hline \multirow{2}{*}{ Weight (kg) } & \multicolumn{9}{|c|}{ Height $(\mathrm{cm})$} \\
\hline & 140 & 145 & 150 & 155 & 160 & 165 & 170 & 175 & 180 \\
\hline 50 & 1.5 & 1.7 & 1.8 & 1.9 & & & & & \\
\hline 55 & 1.5 & 1.6 & 1.8 & 1.9 & 2.0 & & & & \\
\hline 60 & 1.4 & 1.6 & 1.7 & 1.8 & 2.0 & 2.1 & & & \\
\hline 65 & 1.4 & 1.5 & 1.7 & 1.8 & 1.9 & 2.1 & 2.2 & & \\
\hline 70 & 1.3 & 1.5 & 1.6 & 1.8 & 1.9 & 2.0 & 2.2 & 2.3 & \\
\hline 75 & & 1.4 & 1.6 & 1.7 & 1.9 & 2.0 & 2.1 & 2.3 & 2.4 \\
\hline 80 & & 1.4 & 1.5 & 1.7 & 1.8 & 2.0 & 2.1 & 2.2 & 2.4 \\
\hline 85 & & & 1.5 & 1.6 & 1.8 & 1.9 & 2.1 & 2.2 & 2.3 \\
\hline 90 & & & 1.4 & 1.6 & 1.7 & 1.9 & 2.0 & 2.2 & 2.3 \\
\hline 95 & & & & 1.5 & 1.7 & 1.8 & 2.0 & 2.1 & 2.3 \\
\hline 100 & & & & 1.5 & 1.7 & 1.8 & 1.9 & 2.1 & 2.2 \\
\hline 105 & & & & & 1.6 & 1.7 & 1.9 & 2.0 & 2.2 \\
\hline 110 & & & & & & 1.7 & 1.8 & 2.0 & 2.2 \\
\hline
\end{tabular}

Harten JM, BoyneI, Hannah P, Varveris D, Brown A. Effects of a height and weight adjusted dose of local anaesthetic for spinal anaesthesia for elective caesarean section [8]. 
and sufentanil $5 \mu \mathrm{g}$ was added for Group 3. After injecting the drug, we put the patients in a supine position and tilted the left side of the operating table down. From the end of injecting the local anesthetics, the patients' BP and pulse were measured at 2 minute intervals during the first $20 \mathrm{~min}$ and thereafter at $5 \mathrm{~min}$ intervals until the end of the operation. A systolic BP under 90 mmHg or a BP decreased to $20 \%$ of the first measured BP was defined as hypotension; when a patient reached this point, they were given 4-8 mg ephedrine promptly infused intravenously. The sensory block levels were evaluated by pinprick tests that were done at $2 \mathrm{~min}$ intervals after the induction of anesthesia, while the level of motor blockade was assessed using the Modified Bromage scale; movements are recorded on a 4-point scale: 0 = able to raise an extended leg was no motor block; 1 $=$ unable to raise an extended leg, but able to flex the knee; $2=$ unable to flex the knee, but with free movement of the ankle; and $3=$ unable to flex the ankle. The maximum level of sensory block and motor block, the sensory block levels and the Bromage scale $120 \mathrm{~min}$ after the induction of anesthesia were measured as well. We recorded the side-effects that the patients complained of such as nausea, vomiting, pruritus and/or shivering.

The operation began only when the sensory block level was at level T6 or above. The degrees of muscle relaxation during the operation, which the surgeons rated, were classified into one of 4 grades: $1=$ poor, $2=$ fair, $3=\operatorname{good}$ and $4=$ excellent. The intraoperative analgesic effects were estimated as 4 grades: excellent $=$ the patient felt comfortable during operation, no complaints; good = a little discomfort, however no need for additive medication; fair = discomfort, but controlled by additive medication, such as fentanyl, propofol, midazolam, etc.; poor = unable to be controlled even with additive medication. In the case of poor, sevoflurane was applied by mask to alleviate discomfort of the patient. The degree of intra-operative sedation of the parturients was described as $1=$ awake and nervous, 2 = awake and calm, 3 = sleepy but easily aroused and 4 = sleepy and not easily aroused.

Table 2. Demographic Data

\begin{tabular}{lcrr}
\hline & $\begin{array}{c}\text { Group 1 } \\
(\mathrm{n}=35)\end{array}$ & $\begin{array}{r}\text { Group 2 } \\
(\mathrm{n}=35)\end{array}$ & $\begin{array}{r}\text { Group 3 } \\
(\mathrm{n}=35)\end{array}$ \\
\hline Age (yr) & $33.1 \pm 2.5$ & $32.3 \pm 3.8$ & $33.4 \pm 3.8$ \\
Height $(\mathrm{cm})$ & $158.4 \pm 4.4$ & $159.4 \pm 4.6$ & $161.1 \pm 5.2$ \\
Weight $(\mathrm{kg})$ & $66.9 \pm 10.2$ & $68.8 \pm 9.9$ & $71.9 \pm 8.8$ \\
Operation duration (min) & $48.3 \pm 6.1$ & $47.7 \pm 8.5$ & $45.8 \pm 9.4$ \\
Total amount of & $2.3 \pm 0.3$ & $2.6 \pm 0.6$ & $2.6 \pm 0.6$ \\
$\quad$ administrated fluid (L) & & & \\
Apgar score (1 min) & $9.0 \pm 0.4$ & $8.1 \pm 0.2$ & $8.0 \pm 0.3$ \\
Apgar score (5 min) & $9.0 \pm 0.4$ & $9.2 \pm 0.3$ & $9.1 \pm 0.2$ \\
\hline
\end{tabular}

Values are means \pm SDs. P $>0.05$ compared with Group 1 (ANOVA test). Group 1: control, Group 2: sufentanil $2.5 \mu \mathrm{g}$, Group 3: sufentanil $5 \mu \mathrm{g}$.
The patient was previously informed to connect the patient controlled analgesia (PCA) after the surgery when she feels post-operative pain of 4 points on a visual analogue scale (VAS). The effective duration of analgesic duration was evaluated indirectly by recording the interval time from the time point of completion the injection of local anesthetics to that of connecting the PCA to the patient.

The Apgar scores were recorded at 1 and 5 min after birth to assess the health of the newborn infants.

For statistical comparison of the 3 groups, Chi-square tests and Fischer's exact tests were used for the maximum Bromage scale (the max. B/S), the Bromage scale at 120 min after the induction of anesthesia (B/S $120 \mathrm{~min}$ ), the side effects (hypotension, nausea, vomiting, pruritus and/or shivering), degree of muscle relaxation, the intra-operative analgesic effects, and the sedation conditions.

All the other continuous variables were tested for normality Test by using Kolmogorov-Smirnov method. ANOVA test was used for the other observed results, and statistically significant differences were confirmed by Tukey test among the multiple comparison methods. For all of the statistical processes, $\mathrm{P}<$ 0.05 was considered statistically significant. Of the variables investigated in this study, all the continuous variables satisfied the hypothesis tests for normality.

There were no differences between the 3 groups in age, height, weight, or length of operation time, while the mean volumes of bupivacaine used for Group 1, Group 2, and Group 3 were $9.3 \pm 0.7,9.4 \pm 0.6$ and $9.5 \pm 0.7 \mathrm{mg}$, respectively; and there were no statistically significant differences. In addition, the infused amount of intravenous (IV) fluid, the frequency of hypotension and the dosage of ephedrine did not reveal any statistically significant differences (Table 2).

\section{Results}

The maximal level of sensory block was attained above T4 in each group; there were no significant differences between the 3 groups, and only the Group 1 and Group 3 had a significant differences in sensory block level at $120 \mathrm{~min}(\mathrm{P}<0.05)$. The maximum B/S was a score of 3 for $80 \%$ of each group for all 3 groups, and there was no significant difference in response to varying amount of sunfentanil administered (Table 3).

Intraoperative muscle relaxation and analgesia were enhanced with increasing sufentanil dosage with statistically significance $(\mathrm{P}<0.05)$ (Table 4). Effective analgesic duration was measured using PCA connecting time and was recorded as means \pm SD min. There was a significant, positive correlation ( $P$ $<0.05$ ) (ANOVA and Tukey multiple comparison test) between the effective analgesic duration and the amount of sufentanil used as seen among Group 1 (58.0 $\pm 30.8 \mathrm{~min})$, Group 2 (218 \pm 
Table 3. Sensory and Motor Blocks

\begin{tabular}{cccc}
\hline & $\begin{array}{c}\text { Group 1 } \\
(\mathrm{n}=35)\end{array}$ & $\begin{array}{c}\text { Group 2 } \\
(\mathrm{n}=35)\end{array}$ & $\begin{array}{c}\text { Group 3 } \\
(\mathrm{n}=35)\end{array}$ \\
\hline $\begin{array}{l}\text { Sensory blocks } \\
\text { Maximal dermatome level }\end{array}$ & $\mathrm{T} 3.1 \pm 0.3$ & $\mathrm{~T} 2.9 \pm 0.7$ & $\mathrm{~T} 2.9 \pm 0.6$ \\
Sensory block level 120 min & $\mathrm{T} 3.7 \pm 0.5$ & $\mathrm{~T} 3.4 \pm 0.8$ & $\mathrm{~T} 3.4 \pm 0.5^{*}$ \\
Motor blocks & & & \\
Maximal B/S & & & \\
0 & 3 & 0 & 0 \\
1 & 3 & 1 & 2 \\
2 & 29 & 30 & 31 \\
3 & & & \\
B/S 120 min & 3 & 7 & 4 \\
0 & 9 & 10 & 8 \\
1 & 0 & 2 & 5 \\
2 & 20 & 14 & 18 \\
3 & & & \\
\hline
\end{tabular}

Group 1: control, Group 2: sufentanil 2.5 $\mu \mathrm{g}$, Group 3: sufentanil 5 $\mu \mathrm{g}$. Values of sensory blocks are means \pm SDs. ${ }^{*} \mathrm{P}<0.05$ Group 3 vs Group 1 (ANOVA and Tukey multiple comparison test). Values of motor blocks are number of patients. $\mathrm{P}>0.05$ Group 2, 3 vs Group 1 (Linear by linear association), B/S: modified Bromage Scale. 0: No motor block, 1: Unable to raise extended leg (able to flex the knee), 2: Unable to flex knee (able to move the foot only), 3: Unable to flex ankle (unable to move the foot or knee).

Table 4. Quality of Neuromuscular Block and Intraoperative Analgesia

\begin{tabular}{lrrr}
\hline & $\begin{array}{c}\text { Group 1 } \\
(\mathrm{n}=35)\end{array}$ & $\begin{array}{c}\text { Group 2 } \\
(\mathrm{n}=35)\end{array}$ & $\begin{array}{c}\text { Group 3 } \\
(\mathrm{n}=35)\end{array}$ \\
\hline $\begin{array}{l}\text { Quality of neuromuscular block* } \\
\text { Poor }\end{array}$ & 6 & 0 & 1 \\
Fair & 15 & 5 & 1 \\
Good & 14 & 24 & 31 \\
$\quad$ Excellent & 0 & 6 & 2 \\
Quality of intraoperational analgesia* & & & \\
Poor & 26 & 0 & 0 \\
Fair & 6 & 4 & 3 \\
Good & 3 & 14 & 17 \\
Excellent & 0 & 17 & 15 \\
\hline
\end{tabular}

Values are the number of patients. Group 1: control, Group 2: sufentanil $2.5 \mu \mathrm{g}$, Group 3: sufentanil $5 \mu \mathrm{g}$. ${ }^{*} \mathrm{P}<0.05$ Group 2, 3 vs Group 1 (Linear by linear association).

$110.9 \mathrm{~min})$, and Group 3 (282.3 $\pm 110.9 \mathrm{~min})$. The intra-operative sedation of the parturients rose with the increasing amount of sufentanil administered (Table 5).

Hypotension frequency also significantly increased with more sufentanil administered and although Group 3 had more ephedrine administered compared to other two groups, there was no significant difference between Group 1 and Group 2. In terms of nausea, the parturients in sufentanil-using Group 2 and 3 experienced more than those in Group 1 but there was no statistical difference between Group 2 and 3 and vomiting was see in only 3 of the Group 3 patients. Pruritus also was more frequent as more sufentanil was administered (Table 6). There
Table 5. Maximal Sedation Level

\begin{tabular}{lccc}
\hline & $\begin{array}{c}\text { Group 1 } \\
(\mathrm{n}=35)\end{array}$ & $\begin{array}{c}\text { Group 2 } \\
(\mathrm{n}=35)\end{array}$ & $\begin{array}{c}\text { Group 3 } \\
(\mathrm{n}=35)\end{array}$ \\
\hline Awake and nervous & 27 & 2 & 0 \\
Awake and calm & 5 & 16 & 21 \\
Sleepy, easily aroused & 3 & 17 & 14 \\
Sleepy, not easily aroused & 0 & 0 & 0 \\
\hline
\end{tabular}

Values are number of patients. Maximal sedation level rises with statistically significance in accordance to increasing amount of sufentanil. $\mathrm{P}<0.05$ (Linear by linear association). Group 1: control, Group 2: sufentanil $2.5 \mu \mathrm{g}$, Group 3: sufentanil $5 \mu \mathrm{g}$.

Table 6. The Number of Patients with Side Effects

\begin{tabular}{lccc}
\hline & $\begin{array}{c}\text { Group 1 } \\
(\mathrm{n}=35)\end{array}$ & $\begin{array}{c}\text { Group 2 } \\
(\mathrm{n}=35)\end{array}$ & $\begin{array}{c}\text { Group 3 } \\
(\mathrm{n}=35)\end{array}$ \\
\hline Nausea & 0 & $8^{*}$ & $9^{*}$ \\
Vomiting & 0 & 0 & $3^{\dagger}$ \\
Pruritus & 3 & $12^{\ddagger}$ & $24^{\ddagger}$ \\
Shivering & 12 & 9 & 5 \\
Hypotension & 6 & $8^{\S}$ & $14^{\S}$ \\
Ephedrine (mg) & $1.7 \pm 3.9$ & $2.7 \pm 5.4^{\S}$ & $7.5 \pm 10.6^{\S}$ \\
\hline
\end{tabular}

Values are number of patients or means \pm SDs. Group 1: control, Group 2: sufentanil $2.5 \mu$ g, Group 3: sufentanil $5 \mu$ g. *P $<0.05$ Group 2,3 vs Group 1 (Fisher's exact test), ${ }^{\dagger} \mathrm{P}<0.05$ Group 3 vs Group 1,2 (Fisher's exact test), ${ }^{\ddagger} \mathrm{P}<0.05$ Group 2, 3 vs Group 1 (Fisher's exact test), ${ }^{\S} \mathrm{P}<0.05$ Group 2,3 vs Group 1 (Linear by linear association).

was no significant difference among the three groups in terms of shivering and the Apgar scores measured at 1 and 5 minute after birth were all within normal range and no statistical differences among the groups.

\section{Discussion}

Among the anesthesia methods for cesarean section, spinal anesthesia is widely used for its ease of maneuver and fast onset. In addition, the pregnant women can participate in the childbirth experience without risk of the aspiration pneumonia and general anesthesia $[1,2]$. However, the sensory block level may be inadequate and the use of local anesthetics solely may not block the visceral pain adequately due to reasons like abdominal traction [9]. It is also widely known that hypotension from sympathetic nerve block is frequent.

In order to provide long postoperative analgesia and reduce intra-operative visceral pain, there have been many studies on administration of both local anesthetics and opioids [10-15]. Most of these studies have observed that the clinical results with the dose of local anesthetics kept constant, while changing the amount of opioids. Harten et al. [8] proposed using varying amounts of hyperbaric bupivacaine according to the parturient height and weight, which was reported to reduce the incidence 
of side effects such as hypotension and more appropriate block level compared to when it was used at a fixed dosage.

Therefore, we compared the clinical effects of adding sufentanil $2.5 \mu \mathrm{g}$ to $5 \mu \mathrm{g}$ along with hyperbaric bupivacaine according to the parturient height and weight in order to reduce the side effects and to further enhance the advantages.

Morphine is a highly-ionized, hydrophilic opioid, and is characterized by a slow onset time, because it ionizes readily in the subarachnoid space and binds slowly with the opioid receptors of the spinal cord. Morphine also has a long duration because it remains at a high density in the subarachnoid space, and late respiratory depression may be induced by the rostral spread $[16,17]$. On the other hand, the addition of lipophilic opioids, such as fentanyl and sufentanil to local anesthetics, shortens the onset time of the block but produces a, lower incidence of side-effects compared with morphine [11].

Wong et al. [18] reported that more than an addition of 7.5 $\mu \mathrm{g}$ sufentanil revealed more severe pruritus, and a study by Braga et al. [19] revealed that the incidence of pruritus increases as the dosage of the added sufentanil increases. Dahlgren et al. [10] reported that when a fixed amount ( $12.5 \mathrm{mg}$ ) of $0.5 \%$ hyperbaric bupivacaine with $5.0 \mu \mathrm{g}$ or $2.5 \mu \mathrm{g}$ of sufentanil was administered to compare, there was no significant difference in the duration of analgesia, but the pruritus was more frequent when $5 \mu \mathrm{g}$ was used. Therefore, in order to determine which best maximizes the analgesic effects, lessens the side effects from the increasing amount of local anesthetics, and minimizes the complications from injecting opioids in subarachnoid space, the results from uses of the $2.5 \mu \mathrm{g}$ or $5.0 \mu \mathrm{g}$ of sufentanil along with recommended amounts of bupivacaine, according to weight and height, were compared.

There was no difference in the maximum sensory block level, but there was a significant difference in the sensory block level at 120 minutes between Groups 1 and 3. When $5 \mu \mathrm{g}$ of sufentanil was added, there was a longer duration of sensory block, but motor block and recovery rate did not show any significant difference. In addition, intraoperative and postoperative analgesia was enhanced with increasing amount of sufentanil used.

Braga et al. [19] reported that the analgesia duration was lengthened significantly for groups that used $5 \mu \mathrm{g}$ and $7.5 \mu \mathrm{g}$ of sufentanil compared to control or $2.5 \mu \mathrm{g}$ of sufentanil group, and Demiraran et al. [7] reported a similar result as our study, showing a significantly longer analgesic duration for groups that used $1.5 \mu \mathrm{g}, 2.5 \mu \mathrm{g}$, and $5.0 \mu \mathrm{g}$ of sufentanil than that of control group. The present study showed that effective analgesic duration, measured using PCA connecting time, was $218.5 \pm$ 71.8 minutes for $2.5 \mu \mathrm{g}$ sufentanil, $282.3 \pm 110.9$ minutes for $5 \mu \mathrm{g}$. These results are very different from effective analgesic durations of $12.5 \mathrm{mg}$ bupivacaine with the same amounts of sufentanil, $294 \pm 37 \mathrm{~min}$ and $346 \pm 50 \mathrm{~min}$, of Demiraran et al.
[7], which are most likely because less amounts of bupivacaine were used in the present study.

Braga et al. [19] reports the higher sedation frequencies in patients with increasing sufentanil dosages and although the present study confirms the significant increase in the sedation with increasing sufentanil dosage, there was no excessive sedation in any patient who did not wake at light arousal. In the present study, although nausea was significantly more frequent in groups that used sufentanil, there was no significant difference between Group 2 and 3. Vomiting was especially more frequent in Group 3 compared to the other 2 groups, which is a similar trend of higher hypotension frequency with increasing sufentanil dosage. Some studies revealed that there was no difference in the hypotension frequency between sufentanil using groups and the control group, but confirmed the higher nausea frequency in the control group $[7,20]$. There were the results from studies that the addition of other kinds opioids than sufentanil cause nausea and hypotension more frequently $[14,21]$, and so further studies are required.

The incidence of pruritus with the administration of opioid into the subarachnoid space was reported to be $62 \%$ for morphine, $67 \%$ for fentanyl, and $80 \%$ for sufentanil [22]. In particular, pruritus due to the addition of opioids in spinal anesthesia may affect the whole body and there is a higher chance of affecting the trigeminal nerves of face and neck regions [23]. Scott and Fischer [24] suggest a central encephalinergic mechanism for this localization of pruritus. The spinal nucleus of the trigeminal nerve is rich in opioid receptors and is continuous with the substantia gelatinosa and Lissauer tract at C3-C4.

In the present study, the incidence of pruritus rose with the increase in sufentanil dose, which were $34 \%$ and $69 \%$ for Group 2 and Group 3, respectively, and although the incidence was about twice higher in Group 3 than Group 2, and the occurrences appeared as mild to the face and upper chest regions. There was no severe case that needed specific treatments, because of pruritus affecting the whole body. There was no significant difference among the three groups in terms of incidence of shivering and the Apgar scores measured at 1 minute and 5 minutes after birth.

In conclusion, intra-operative muscle relaxation and the analgesia were enhanced with increasing dosage of sufentanil. However, although the effective analgesic duration was longer for Group 3 than Group 2, because the vomiting, hypotension, and pruritus frequencies were higher in Group 3 than Group 2 , it is recommended to use $2.5 \mu \mathrm{g}$ of sunfentanil over $5.0 \mu \mathrm{g}$ with the amounts of $0.5 \%$ hyperbaric bupivacine, which varied according to the parturients' height and weight, in order to lower the possible side effects and to lengthen the effective analgesic duration. 


\section{References}

1. Randalls B, Broadway JW, Browne DA, Morgan BM. Comparison of four subarachnoid solutions in a needle-through-needle technique for elective caesarean section. Br J Anaesth 1991; 66: 314-8.

2. Hunt CO, Naulty JS, Bader AM, Hauch MA, Vertikar JV, Datta S, et al. Perioperative analgesia with subarachnoid fentanyl-bupivacaine for cesarean delivery. Anesthesiology 1989: 71; 535-40.

3. Dickenson AH. Spinal cord pharmacology of pain. Br J Anaesth 1995; 75: 193-200.

4. Katz J, Kavanagh BP, Sandler AN, Nierenberg H, Boylan JF, Friedlander $\mathrm{M}$, et al. Preemptive analgesia. Clinical evidence of neuroplasticity contributing to postoperative pain. Anesthesiology 1992; 77: 43946.

5. Abouleish E, Rawal N, Fallon K, Hernandez D. Combined intrathecal morphine and bupivacaine for cesarean section. Anesth Analg 1988; 67: 370-4.

6. Courtney MA, Bader AM, Hartwell B, Hauch M, Grennan MJ, Datta S. Perioperative analgesia with subarachnoid sufentanil administration. Reg Anesth 1992; 17: 274-8.

7. Demiraran Y, Ozdemir I, Kocaman B, Yucel O. Intrathecal sufentanil (1.5microg) added to hyperbaric bupivacaine (0.5\%) for elective cesarean section provides adequate analgesia without need for pruritus therapy. J Anesth 2006; 20: 274-8.

8. Harten JM, Boyne I, Hannah P, Varveris D, Brown A. Effects of a height and weight adjusted dose of local anaesthetic for spinal anaesthesia for elective Caesarean section. Anaesthesia 2005; 60: 348-53.

9. Pedersen H, Santos AC, Steinberg ES, Schapiro HM, Harmon TW, Finster M. Incidence of visceral pain during cesarean section: the effect of varying doses of spinal bupivacaine. Anesth Analg 1989; 69: 46-9.

10. Dahlgren G, Hultstrand C, Jakobsson J, Norman M, Eriksson EW, Martin H. Intrathecal sufentanil, fentayl, or placebo added to bupivacaine for cesarean section. Anesth Analg 1997; 85: 1288-93.

11. Belzarena SD. Clinical effects of intrathecally administered fentanyl in patients undergoing cesarean section. Anesth Analg 1992; 74: 653-7.

12. Parpaglioni R, Baldassini B, Barbati G, Celleno D. Adding sufentanil to levobupivacaine or ropivacaine intrathecal anaesthesia affects the minimum local anaesthetic dose required. Acta Anaesthesiol Scand 2009; 53: 1214-20.

13. Braga Ade F, Frias JA, Braga FS, Pinto DR. Spinal block with 10mg of hyperbaric bupivacaine associated with 5 microg of sufentanil for cesarean section. Study of different volumes. Rev Bras Anestesiol 2010; 60: 121-9.

14. Lee JH, Chung KH, Lee JY, Chun DH, Yang HJ, Ko TK, et al. Comparison of fentanyl and sufentanil added to $0.5 \%$ hyperbaric bupivacaine for spinal anesthesia in patients undergoing cesarean section. Korean J Anesthesiol 2011; 60: 103-8.

15. Qian XW, Chen XZ, Li DB. Low-dose ropivacaine-sufentanil spinal anaesthesia for caesarean delivery: a randomized trial. Int J Obstet Anesth 2008; 17: 309-14.

16. Ummenhofer WC, Arends RH, Shen DD, Bernards CM. Comparative spinal distribution and clearance kinetics of intrathecally administered morphine, fentanyl, alfentanil, and sufentanil. Anesthesiology 2000; 92: 739-53.

17. Abouleish E, Rawal N, Fallon K, Hernandez D. Combined intrathecal morphine and bupivacaine for cesarean section. Anesth Analg 1988; 67: 370-4.

18. Wong CA, Scavone BM, Loffredi M, Wang WY, Peaceman AM, Ganchiff JN. The dose-response of intrathecal sufentanil added to bupivacaine for labor analgesia. Anesthesiology 2000; 92: 1553-8.

19. Braga Ade F, Braga FS, Potério GM, Pereira RI, Reis E, Cremonesi E. Sufentanil added to hyperbaric bupivacaine for subarachnoid block in Caesarean section. Eur J Anaesthesiol 2003; 20: 631-5.

20. Vyas N, Sahu DK, Parampill R. Comparative study of intrathecal sufentanil bupivacaine versus intrathecal bupivacaine in patients undergoing elective cesarean section. J Anaesthesiol Clin Pharmacol 2010; 26: 488-92.

21. Choi JH, Kong MH, Lim SH, Lee MK. Comparison of intrathecal meperidine, fentanyl, or placebo added to $0.5 \%$ hyperbaric bupivacaine for cesarean section. Korean J Anesthesiol 2000; 38: 49-57.

22. Kjellberg F, Tramèr MR. Pharmacological control of opioid-induced pruritus: a quantitative systematic review of randomized trials. Eur J Anaesthesiol 2001; 18: 346-57.

23. Ballantyne JC, Loach AB, Carr DB. Itching after epidural and spinal opiates. Pain 1988; 33: 149-60.

24. Scott PV, Fischer HB. Spinal opiate analgesia and facial pruritus: a neural theory. Postgrad Med J 1982; 58: 531-5. 